\title{
Радиочастотная катетерная деструкция непароксизмальных форм фибрилляции предсердий
}

\author{
Доронин А. В. ${ }^{1}$, Суслина Ю. И. ${ }^{2}$, Резник А. С. ${ }^{2}$, Ханенова В. А. ${ }^{2}$, Марушко Е. Ю. ${ }^{2}$, \\ Мешкова М. С. ${ }^{2}$
}

${ }^{1}$ Национальная медицинская академия последипломного образования имени П. Л. Шупика (Киев) 2ГУ «Научно-практический медицинский центр детской кардиологии

и кардиохирургии МЗ Украины» (Киев)

\begin{abstract}
В статье анализируется собственный опыт радиочастотной катетерной деструкции непароксизмальных форм фибрилляции предсердий (ФП). Проанализированы результаты 120 первичных последовательных процедур. Персистирующая форма ФП наблюдалась у 93 (77,5\%) пациентов, длительно персистирующая - у $27(22,5 \%)$.

Среднее время рентген-экспозиции составило $32,1 \pm 8,1$ мин., количество аппликаций $-109,4 \pm 19,4$, длительность процедуры $-2,7 \pm 0,6$ часа.

У $1(0,8 \%)$ больного после вмешательства возникла предсердная тахикардия, у $1(0,8 \%)-$ левостороннее трепетание предсердий, рецидив ФП произошел у $34(28,3 \%)$ пациентов. Синусовый ритм сохранился без применения антиаритмических препаратов на протяжении года у $80(66,7 \%)$ пациентов. Антиаритмическими препаратами удалось удержать синусовый ритм либо приступы тахикардии стали редкими еще у 23 $(19,2 \%)$ пациентов. Таким образом, положительный эффект удалось получить у $103(85,8 \%)$ пациентов.

Можно сделать вывод, что данная методика является достаточно эффективной при непароксизмальных формах ФП.
\end{abstract}

Ключевые слова: фибрилляция предсердий, катетерная деструкция, фрагментированные электрограммы.

Катетерная деструкция зарекомендовала себя как эффективный метод лечения фибрилляции предсердий (ФП), и популярность этого метода продолжает расти [1]. Применяемая большинством авторов широкая изоляция легочных вен, эффективная при пароксизмальной форме ФП, оказалась менее эффективной при непароксизмальных формах [2]. Поэтому продолжаются поиски адекватной стратегии. Одна из этих стратегий - дополнение изоляции легочных вен созданием линий аппликаций в левом предсердии [3]. Однако более поздние исследования показали, что такие линии не улучшают результаты [4]. Многие авторы считают, что фрагментированные электрограммы являются морфологическим субстратом ФП [3, 5]. Но исследования последних лет показывают, что нанесение аппликаций в местах регистрации фрагментированных электрограмм также не улучшает результаты катетерной деструкции непароксизмальных форм ФП [3]. Наконец, существует методика, при которой наносятся аппликации в местах регистрации фрагментированных электрограмм без изоляции легочных вен [6, 7].

Условно можно выделить три основные группы методик катетерной деструкции непароксизмальных форм ФП: 1) пошаговая стратегия: изоляция легочных вен, создание линий аппликаций, устранение различных видов электрограмм в разной последовательности и сочетаниях; 2) выполнение исключительно широкой изоляции легочных вен; 3) нанесение аппликаций в местах регистрации фрагментированных электрограмм без изоляции легочных вен.

После проведения радиочастотной катетерной деструкции при непароксизмальной форме ФП синусовый ритм на протяжении года без применения антиаритмических препаратов сохраняется у 35-69\% пациентов [3]. После катетерной деструкции до $50 \%$ рецидивов приходится на предсердные тахикардии и трепетание предсердий, субстрат для которых возникает в результате нанесения аппликаций [3].

Цель работы - проанализировать собственный опыт радиочастотной катетерной деструкции непароксизмальных форм ФП.

Материалы и методы. В ГУ «Научно-практический медицинский центр детской кардиологии и кардиохирургии МЗ Украины» в период с 01.2013 г. по 12.2015 г. было произведено 127 первичных последовательных катетерных деструкций у пациентов с персистирующей и длительно персистирующей формами ФП. Была утеряна связь с 7 пациентами. В группу для анализа вошли 120 (94,5\%) пациентов. 
В группе было $47(39,1 \%)$ женщин. Средний возраст пациентов составил $58,7 \pm 6,5$ года.

Персистирующая форма ФП наблюдалась у 93 $(77,5 \%)$ пациентов, длительно персистирующая - у 27 $(22,5 \%)$. Среди пациентов с персистирующей формой ФП у $14(15,1 \%)$ было истмус-зависмое трепетание предсердий (ТП), у $1(1,1 \%)$ - левостороннее ТП.

У $62(51,7 \%)$ пациентов диагностирована гипертоническая болезнь, у 3 (2,5\%) - заболевания щитовидной железы, у $13(10,8 \%)$ пациентов - ИБС, $9(7,5 \%)$ перенесли аортокоронарное шунтирование, у $3(2,5 \%)$ пациентов вынолнено протезирование аортального клапана, у $2(1,7 \%)$ - митрального, у $3(2,5 \%)$ пациентов выявлен сахарный диабет, один $(0,8 \%)$ пациент перенес инсульт.

Всем пациентам перед процедурой назначались антикоагулянты в течение четырех недель. Антиаритмическая терапия не прекращалась.

Применялся интубационный наркоз. Выполнялась двойная транссептальная пункция. Деструкционный электрод извлекался и протирался влажной салфеткой после каждых 15-20 аппликаций. После изоляции легочных вен наносились аппликации в местах регистрации фрагментированных электрограмм в левом предсердии на фоне в/в капельного введения 300 мг кордарона. В правом предсердии наносились по 3 аппликации в устьях верхней и нижней полых вен. Выполнялась линия аппликаций по задней стенке правого предсердия между полыми венами. Во время нанесения аппликации синусовый ритм восстанавливался в единичных случаях, в большинстве случаев проводилась ЭИТ. Мощность воздействия - 35 Ватт, температура $-55^{\circ} \mathrm{C}$, время аппликации - 40 секунд.

В послеоперационном периоде больные наблюдались минимум 2 раза (через 1 и 3 месяца после процедуры) с записью холтеровской и обычной ЭКГ. Затем холтеровская и обычная ЭКГ проводились через 6 месяцев и через 1 год, в дальнейшем - по показаниям. Пациенты были ознакомлены с методами контроля сердечного ритма.

Результаты. Среднее время рентген-экспозиции составило $32,1 \pm 8,1$ мин. Количество аппликаций $109,4 \pm 19,4$. Длительность процедуры - 2,7士0,6 часа. Отмечалась выраженная тенденция к уменьшению рентген-экспозиции и длительности процедуры по мере накопления опыта. При этом число аппликаций оставалось стабильным.

Рецидив ФП на протяжении 1 года произошел у 34 $(28,3 \%)$ пациентов, еще у $4(3,3 \%)$ возникло типичное ТП, у $1(0,8 \%)$ - предсердная тахикардия, у $1(0,8 \%)$ - левостороннее ТП. У 3 (2,5\%) пациентов зафиксированы «немые формы» ФП. Синусовый ритм сохранялся без применения антиаритмических препаратов на протяжении года у $80(66,7 \%)$ пациентов. Антиаритмическими препаратами удалось удержать синусовый ритм либо приступы тахикардии стали редкими еще у $23(19,2 \%)$ пациентов. Таким образом, положительный эффект удалось получить у $103(85,8 \%)$ пациентов.

Осложнения возникли у $3(2,4 \%)$ пациентов: 1 $(0,8 \%)$ случай - аневризма бедренной артерии, потребовавшая хирургического вмешательства, $1(0,8 \%)-$ гематома бедра в месте пункции, $1(0,8 \%)$ - временная AВ-блокада, потребовавшая наружной электрокардиостимуляции.

Полученные данные демонстрируют, что можно получать хорошие результаты катетерной деструкции ФП без применения навигационных систем и охлаждаемых электродов. Мы не ставим задачу добиться прекращения ФП путем нанесения аппликаций, что делает процедуру более прогнозированной. Изоляция устьев легочных вен и нанесение аппликации в местах регистрации фрагментированных электрограмм электродами без функции охлаждения способствует уменьшению количества осложнений и сохраняет больше жизнеспособного миокарда предсердий, что потенциально увеличивает число положительных результатов. Также наблюдается минимальное число случаев левостороннего ТП.

Хотя в публикациях сообщается о сериях, в которых рентген-экспозиция не превышает менее 1 минуты [7], большинство авторов сообщают о рентген-экспозиции более 20 минут. Наши рентген-экспозиция и длительность процедуры находятся в пределах значений, публикуемых в литературе. Данная методика актуальна в условиях Украины еще и в связи со значительным снижением себестоимости процедуры.

Выводы. Изоляция устьев легочных вен с дополнительным нанесением аппликаций в местах регистрации фрагментированных электрограмм без применения навигационных систем и электродов с функцией охлаждения у пациентов с непароксизмальными формами ФП эффективна и безопасна.

\section{Литература}

1. Updated world wide survey on the methods, efficacy, and safety of catheter ablation for human atrial fibrillation / Cappato R., Calkins H., ChenS. A. et al. // Circ. Arrhythm. Electrophysiol. - 2010. - Vol. 3. - P. 32-38.

2. Okamatsu H., Okumura K. Strategy and Outcome of Catheter Ablation for Persistent Atrial Fibrillation // Circulation Journal. - Vol. 82. - January 2018. - P. 2-9.

3. HRS/EHRA/ECAS/APHRS/SOLAECE expert consensus statement on catheter and surgical ablation of atrial fibrillation / Calkins H., Hindricks G., Cappato R. et al. // Heart Rhythm. - 2017. - Vol. 14. - P. 275-444.

4. Pulmonary vein isolation versus defragmentation: the CHASEAF clinical trial / Vogler J. et al. // J Am CollCardiol. - 2015. - Vol. 66 (24). - P. 2743-2752.

5. A new approach for catheter ablation of atrial fibrillation: mapping of the electrophysiologic substrate / Nademanee K. et al. // J Am CollCardiol. - 2004. - Vol. 43 (11). - P. 2044-2053. 
6. Ablation of complex fractionated electrograms is useful for catheter ablation of persistent atrial fibrillation: Protagonist point of view / Oketani N., Seitz J., Salazar M. et al. // Heart Rhythm. - Vol. 13. - № 10, October. - 2016. P. 2098-2100.
7. AF Ablation Guided by Spatiotemporal Electrogram Dispersion Without Pulmonary Vein Isolation / Seitz J., Bars C., Kalifa J. et al. // J Am CollCardiol. - - 2017. Vol. 69. - № 3. - P. 303-321.

\title{
Radiofrequency catheter ablation of non-paroxysmal atrial fibrillation
}

\author{
Doronin A. ${ }^{1}$, Suslina Y. ${ }^{2}$, Riznyk A. ${ }^{2}$, Khanenova V. ${ }^{2}$, Marushko Y. ${ }^{2}$, Meshkova M. ${ }^{2}$ \\ ${ }^{1}$ Ukrainian National Medical Postgraduate Academy (Kyi) \\ 2 Ukrainian Children's Cardiac Center (Kyiv)
}

In this article we analyzed our own experience of non-paroxysmal atrial fibrillation (AF) catheter ablations by conventional $4 \mathrm{~mm}$ tip non-irrigated catheters. The results of 120 primary sequential procedures are studied. Persistent form of AF was observed in $93(77.5 \%)$ patients, long-standing persistent - in $27(22.5 \%)$.

The average time of X-ray exposure was $32.1 \pm 8.1$ minutes, the number of applications was $109.4 \pm 19.4$, the duration of the procedure was $2.7 \pm 0.6$ hours.

In $1(0.8 \%)$ patient after the intervention there was an atrial tachycardia, in $1(0.8 \%)$ - left atrial flutter. The recurrence of AF occurred in $34(28.3 \%)$ patients. The sinus rhythm was preserved during the first year after ablation without the use of antiarrhythmic drugs in $80(66.7 \%)$ patients. With the antiarrhythmic drugs administration we were able to maintain a sinus rhythm or make arrhythmia attacks rare in $23(19.2 \%)$ patients. Thus, a positive effect of ablation was obtained in 103 $(85.8 \%)$ patients.

So, we can conclude that this ablation technique is quite effective in non-paroxysmal forms of AF.

Key words: atrial fibrillation, catheter ablation, fragmented electrograms.

\section{Радіочастотна катетерна деструкція непароксизмальних форм фібриляції передсердь}

\author{
Доронін О. В. ${ }^{1}$, Сусліна Ю. І. ${ }^{2}$, Різник О. С. ${ }^{2}$, Ханенова В. 0. ${ }^{2}$, Марушко Е. Ю. ${ }^{2}$, Мешкова М. С. ${ }^{2}$ \\ ${ }^{1}$ Національна медична академія післядипломної освіти імені П. Л. Шупика (Київ) \\ ${ }^{2}$ ДУ «Науково-практичний медичний центр дитячої кардіології і кардіохірургії МОЗ України» (Київ)
}

В статті аналізується власний досвід радіочастотної катетерної деструкції непароксизмальних форм фібриляції передсердь (ФП). Проаналізовані результати 120 первинних послідовних процедур. Персистуюча форма ФП спостерігалась у $93(77,5 \%)$ пацієнтів, тривало персистуюча - у 27 (22,5\%).

Середній час рентген-експозиції склав $32,1 \pm 8,1$ хв., кількість аплікацій $-109,4 \pm 19,4$, тривалість процедури $2,7 \pm 0,6$ години.

В одного $(0,8 \%)$ пацієнта після втручання виникла передсердна тахікардія, у $1(0,8 \%)$ - лівобічне тріпотіння передсердь. Рецидив ФП виник у $34(28,3 \%)$ пацієнтів. Синусовий ритм зберігався без застосування антиаритмічних препаратів упродовж року у $80(66,7 \%)$ пацієнтів. Антиаритмічними препаратами вдавалося утримувати синусовий ритм або напади тахікардії стали рідкими ще у $23(19,2 \%)$ пацієнтів. Таким чином, позитивний ефект вдалося отримати у $103(85,8 \%)$ пацієнтів.

Можна зробити висновок, що дана методика є достатньо ефективною при непароксизмальних формах ФП.

Ключові слова: фібриляція передсердь, катетерна деструкція, фрагментовані електрограми. 